\title{
A NEW MULTIVARIATE NONLINEAR MODEL TO HANDLE THE VOLATILITY TRANSMISSION
}

\author{
S. B. Ebrahimi ${ }^{1 *} \&$ F.R. Olyaee ${ }^{2}$ \\ ${ }^{1}$ Department of Industrial Engineering \\ K.N.Toosi University of Technology \\ Tehran, Iran \\ b_ebrahimi@kntu.ac.ir \\ ${ }^{2}$ Department of Industrial Engineering \\ Iran University of Science and Technology, Tehran, Iran \\ rouhi@ifcenter.ir
}

\begin{abstract}
Price volatility of stocks is an important issue in stock markets. It should also be taken into account that the stochastic nature of volatility affects decision-makers' minds to a great extent. Therefore, predicting price volatility could help them make proper decisions. In this paper, a new multivariate fractionally integrated generalised autoregressive conditional heteroscedasticity (MFIGARCH) model is proposed to handle the price volatility in stocks. In this model, a long-term parameter is considered and estimated along with other parameters. In estimating the parameters of this nonlinear model, the maximum likelihood estimation method, which could be solved by standard econometric packages, is applied. However, these packages are no longer efficient when the size of the model increases. Thus meta-heuristic approaches, which stochastically seek optimal or near-optimal solutions, were used. In this paper, the well-known Particle Swarm Optimisation (PSO) meta-heuristic method is used for solving the suggested multivariate FIGARCH model. Hence the main objective of this paper is to introduce a new model for addressing the stock price volatility (i.e., the development of FIGARCH to create the MFIGARCH model) and to apply an efficient estimation method (i.e. PSO) for finding the parameters of the problem.
\end{abstract}

\section{OPSOMMING}

Die wisselvalligheid van die aandeelprys is ' $n$ belangrike kwessie vir aandelemarkte. Die stogastiese aard van dié wisselvalligheid beïnvloed besluitnemers op ' $n$ groot skaal en die voorspelling van die wisselvalligheid kan die besluitneming verbeter. ' $n$ Nuwe, meerveranderlike gedeeltelik geïntegreerde veralgemeende outoregressiewe voorwaardelike heteroskedastisiteit (MFIGARCH) model word voorgestel om die wisselvalligheid in aandeelpryse te hanteer. In hierdie model word, onder andere, ' $n$ langtermyn parameter oorweeg en beraam. Vir die beraming van parameters in hierdie nielineêre model word die maksimum waarskynlikheidsmetode (wat opgelos kan word deur middel van standaard ekonometriese pakkette) toegepas. Hierdie pakkette is egter oneffektief wanneer die model vergroot. Dus word meta-heuristiese, wat optimale of bynaoptimale oplossings stogasties soek, ingespan. Die welbekende partikel swerm optimering metode word gebruik vir die oplos van die voorgestelde meerveranderlike model. Die hoof doel van hierdie studie is om die nuwe meerveranderlike model om die wisselvalligheid in aandeelprys aan te spreek, bekend te stel en om effektiewe parameter beraming deur middel van partikel swerm optimering toe te pas.

\footnotetext{
" Corresponding author
} 


\section{$1 \quad$ INTRODUCTION}

Studying price volatility in stock markets indicates that the volatility of a stock depends greatly on both the volatility of other stocks and that of the same stock in previous periods. It has been shown that autoregressive conditional heteroscedasticity (ARCH) and the generalised ARCH (GARCH) models are reliable work horses in modelling time-varying variances of economic time series data in univariate cases. Most authors have attempted to develop these models for multivariate dimensions. Multivariate volatility models have many excellent financial applications in portfolio selection, asset allocation, and calculation of the value at risk for the case of multiple assets [1]. In recent decades, international financial markets have been syndicated due to globalisation. This has made financial market stakeholders aware of how volatility affects the markets over time. Some typical applications of the multivariate GARCH (MGARCH) model are in optimising portfolios [2], pricing assets and derivatives [3], computing the value at risk [4,5], hedging futures [6], transmitting volatility and allocating asset [7], estimating systemic risk in banking [8], determining leverage effect [9], estimating volatility momentum function [3,10,11], nonlinear programming [12], avoiding currency exposure risk [13,14], calculating property portfolio minimum capital risk [15], ascertaining incorrect tests of MGARCH models [16], modelling changing variance in an exchange rate structure [17], and analysing individual financial markets [18].

To analyse the volatility spillover system between different exchange rates in the European monetary system, Kearney and Patton [19] applied a multivariate GARCH model. The volatility spillover among large and small capitalisation stocks was analysed by the multivariate GARCH model's BEKK (Baba, Engle, Kraft, and Kroner) parameterisation [20]. Moreover, volatility and shock transmission mechanisms were studied in US equity, Gulf equity, and global crude oil markets [21], in which the trend of volatility was from the oil market to Gulf equity markets. The opposite trend was identified only in the case of Saudi Arabia.

In this paper, a multivariate fractionally integrated GARCH (FIGARCH) model was applied to estimate simultaneously the mean and conditional variance of daily returns of three indices: the automotive and parts manufacturing industry, financial intermediations (leasing), and the machinery and equipment index (Tehran Stock Exchange). In this study, a multivariate FIGARCH model was employed specifically because it allows the simultaneous study of volatility transmission in three different indices.

The parameters of the aforementioned models are most often estimated using a maximum likelihood estimation method in standard econometric software. However, as the problem increases in size, this software may not be able to handle the model and find a solution. Therefore, heuristic or meta-heuristic approaches are used to resolve this difficulty. Among the existing studies, Malik and Hammoudeh [21] employed the simulated annealing metaheuristic method for finding the parameters of the GARCH model. Later, Winker and Maringer [23] applied a threshold accepting method and demonstrated the superiority of this method over standard numerical econometric packages. These studies provided the motivation for the present investigation to apply a particle swarm optimisation (PSO) metaheuristic approach to estimate the parameters of the proposed multivariate FIGARCH model.

The rest of this paper is organised as follows: In Section 2, an overview of the existing models in the literature is presented, including univariate and multivariate GARCH, univariate FIGARCH, and BEKK models. In Section 3, the proposed model is introduced, and Section 4 includes an estimation of the parameters of the proposed multivariate FIGARCH model. Implementation of the proposed FIGARCH in the Iranian stock market is presented in Section 5, and a summary of the paper's key findings and its conclusion are provided in Section 6. 


\section{REVIEW OF BASE MODELS}

Generally, a time series analysis of economic data is based on observations, and is obtained from procedures such as the behaviour of short- and long-term interest rates, the inflation rate, stock prices, etc. Typically, a 'time series' is defined as a random process in which stochastic variables (one-dimensional or multi-dimensional) are determined on some state space $\varphi$. One-dimensional variables usually lead to univariate econometric models, and multi-dimensional variables often result in multi-dimensional econometric models. Moreover, since these random variables are indicated by time, and since the observations are recorded at regular intervals, time indices can only take integer values $[24,25]$. This process is indicated as follows:

$$
R=\left(R_{t}, t \in T\right)
$$

where $\mathrm{T}$ set index denotes the positive integers set or natural numbers set. In this paper, an auto-regressive process is considered for the returns of the stock index in which the past value of random variables signifies their behaviour:

$$
R_{t}=\theta_{0}+\theta_{1} R_{t-1}+\theta_{2} R_{t-2}+\theta_{3} R_{t-3}+\ldots+\theta_{m} R_{t-m}+\varepsilon_{t}
$$

In what follows, an overview is provided on Auto Regressive Moving Average(ARMA), univariate and multivariate GARCH, and fractionally integrated GARCH (FIGARCH) models.

\subsection{Univariate and multivariate GARCH models}

\subsubsection{Univariate form}

An important tool for estimating model parameters is the technique of maximum likelihood evaluation. Assuming normal distribution for $R_{t}$ and based on past observations, the maximum likelihood technique can be applied in the $\operatorname{GARCH}(p, q)$ model, which is indicated in the following problem [25]:

$$
\begin{aligned}
& \max :-\frac{1}{2} \sum_{t=1}^{T} \log h_{t}-\frac{1}{2} \sum_{t=1}^{T} \log \frac{\varepsilon_{t}^{2}}{h_{t}} \\
& \text { s.t: } \quad h_{t}=\alpha_{o}+\sum_{i=1}^{q} \alpha_{i} \varepsilon_{t-i}^{2}+\sum_{j=1}^{p} \beta_{j} \sigma_{t-j}^{2} \quad \forall t=1, \ldots, T \\
& \sum_{i=1}^{q} \alpha_{i}+\sum_{j=1}^{p} \beta_{j}<1 \\
& h_{t} \geq 0 \\
& \alpha_{i} \geq 0 \\
& \beta_{j} \geq 0 \\
& \begin{array}{l}
\forall t=1, \ldots, T \\
\forall t=1, \ldots, T \\
\forall t=1, \ldots, T
\end{array}
\end{aligned}
$$

In the above equations, $h_{t}$ is a conditional variance where $\varepsilon_{t-1}=\left(\varepsilon_{t} \mid I_{t-1}\right)$ shows the vector of past values. Modelling financial time series $\left(R_{t}\right)$ is important, as empirical evidence does not show any characteristic of time dependence for level process $\left(R_{t}\right)$. It reveals instead a particular characteristic of time dependence for the volatility process. Modelling the volatility of the series might occasionally be more important for risk quantifying, which involves a specific trading strategy. This paper therefore does not consider the conditional variance of the noise, i.e. $E=\left(\varepsilon_{t}^{2} \mid I_{t-1}\right)$ as time dependent, but assumes time dependence through an autoregressive equation for the squared error terms, as shown below: 


$$
E\left(\varepsilon_{t}^{2} \mid I_{t-1}\right)=h_{t}=\alpha_{o}+\sum_{i=1}^{q} \alpha_{i} \varepsilon_{t-i}^{2}+\sum_{j=1}^{p} \beta_{j} \sigma_{t-j}^{2}
$$

The second constraint $\left(\sum_{i=1}^{q} \alpha_{i}+\sum_{j=1}^{p} \beta_{j}<1\right)$ is the stationarity condition. A significant issue in studying time series is the stationarity of the properties of the time series, which helps its predictability. A very important part of modelling is to impose the stationarity constraint. With enough long-term averages, one can estimate mean, variance, and autocorrelations, if $\left(R_{t}\right)$ is stationary. Covariance (or second-order) stationarity is a stochastic process with a finite mean and variance, i.e., if, for all $t, t-s$,

$$
\begin{aligned}
& E\left(R_{t}\right)=E\left(R_{t-s}\right)=\mu \\
& E\left[\left(R_{t}-\mu\right)^{2}\right]=E\left[\left(R_{t-s}-\mu\right)^{2}\right]=\sigma_{R}^{2} \\
& E\left[\left(R_{t}-\mu\right)\left(R_{t-s}-\mu\right)\right]=E\left[\left(R_{t-i}-\mu\right)\left(R_{t-i-s}-\mu\right)\right]=\gamma_{s}
\end{aligned}
$$

In the above equations, $\mu, \sigma_{R}^{2}$, and $\gamma_{s}$ are constants. Simply, a time series is covariance stationarity if its mean and all auto-covariances are not time varying. Finally, parameters $\alpha_{0}, \alpha$, and $\beta$ are all considered to have positive values; i.e., $\alpha$ and $\beta$ belong to the space of $q$ - and $p$-dimensional real vectors with positive components.

\subsubsection{Multivariate form}

Several multivariate extensions of univariate GARCH, with practical applications, have been proposed in the literature (as can be seen in [24]). Here, a brief description is presented of the Vech and BEKK models as MGARCH models.

When the term 'error' is a multivariate process, $\varepsilon_{t}$ must be defined as a $n \times 1$ vector. Hence, we have $\varepsilon_{t-1}=\left(\varepsilon_{t} \mid I_{t-1}\right)=0$ and $\varepsilon_{t-1}=\left(\varepsilon_{t} \varepsilon_{t}^{\prime} \mid I_{t-1}\right)=H_{t}$; where conditional covariance matrix $H_{t}$ is a non-trivial function of the information set and $H_{t}$ and $\varepsilon_{t} \varepsilon_{t}^{\prime}$ are symmetric matrices by denoting Vech operator. In this model, Vech is the operator that includes stacking up the lower triangular and diagonal portions of the columns of a symmetric matrix into a vector.

$$
\operatorname{vech}\left(H_{t}\right)=\operatorname{vech}(C)+\sum_{i=1}^{q} A_{i} \operatorname{vech}\left(\varepsilon_{t-i} \varepsilon_{t-i}^{\prime}\right)+\sum_{j=1}^{p} B_{j} \operatorname{vech}\left(H_{t-j}\right)
$$

In the above equation, the matrices $A_{i}$ and $B_{j}$ are of size $\frac{n(n+1)}{2} \times \frac{n(n+1)}{2}$ and $C$ is an $n$ $x \mathrm{n}$ symmetric matrix. The discussed model is a general extension of the univariate GARCH $(p, q)$ model to a multivariate framework model [25]. Since ensuring the positive definiteness of $H_{t}$ in a Vech model is difficult without imposing rigid restrictions, Engle and Kroner [25] proposed the BEKK model. In the BEKK parameterisation, $H_{t}$ is defined as a positive semi-definite matrix, which reduces the number of parameters to be estimated. Since the goal of this paper is to adapt the perception of long term memory and fractional differencing in a multivariate framework, the parameterisation and logic followed in the BEKK specification is the main point of attraction.

Also, considering that BEKK is a popular and well-known model used in the volatility modelling of finance, the conditional variance-covariance matrices in the $\operatorname{BEKK}(1,1, K)$ model can be expressed as:

$$
H_{t}=C^{* T} C^{*}+\sum_{k=1}^{K} A_{k}^{* T} \varepsilon_{t-1}^{T} \varepsilon_{t-1} A_{k}^{*}+\sum_{k=1}^{K} G_{k}^{* T} H_{t-1} G_{k}^{*}
$$

In the above equation $A^{*}, G^{*}$, and $C^{*}$ are $n \times n$ matrices, which are not necessarily symmetric. Comparing the BEKK model and Vech specification (13) from a numerical 
optimisation point of view, the BEKK model with application of higher order polynomial representation increases the constraints' nonlinearity.

\subsection{Univariate and multivariate FIGARCH}

\subsubsection{Univariate form}

In terms of squared residuals, the $\operatorname{GARCH}(1,1)$ model can be written as an ARMA $(1,1)$ model. In the same sense, the $\operatorname{GARCH}(p, q)$ model can be simply rewritten as

$$
\phi(L) \varepsilon_{t}^{2}=a+b(L) u_{t}
$$

Where

$$
\begin{aligned}
& u_{t}=\varepsilon_{t}^{2}-\sigma_{t}^{2} \\
& \phi(L)=1-\phi_{1} L-\phi_{2} L^{2}-\ldots-\phi_{m} L^{m} \\
& b(L)=1-b_{1} L-b_{2} L^{2}-\ldots-b_{q} L^{q}
\end{aligned}
$$

assuming $\mathrm{m}=\max (\mathrm{p}, \mathrm{q})$ and $\varphi_{i}=a_{i}+b_{i}$. Obviously, Equation (15) indicates an ARMA (m, q) process in terms of squared residuals, $\varepsilon_{t}^{2}$ where $u_{t}$ is the Martingale Difference Sequence (MDS) disturbance term. GARCH models with high persistence and polynomial $\varphi(z)=0$ (unit root) are called the Integrated GARCH (IGARCH) model [26], for which unconditional variance does not exist. If we impose high persistence and long term memory in the conditional variance, the IGARCH models will get too complicated. In order to avoid this, the ARMA ( $m, q)$ process in (15) can be extended to an ARFIMA ( $m, d, q)$ process as follows:

$$
\phi(L)(1-L)^{d} \varepsilon_{t}^{2}=a+b(L) u_{t}
$$

where all roots of $\phi(z)=0$ and $b(z)=0$ lie outside the unit circle. When $d=0$, the ARFIMA model is reduced to the usual GARCH model; when $d=1$, the ARFIMA model turns into an IGARCH model. Also, when we have $0<d<1$, fractionally differenced squared residuals, $(1-L)^{d} \varepsilon_{t}^{2}$ follow an ARMA $(m, q)$ process of a stationarity nature. The ARFIMA $\varepsilon_{t}^{2}$ process in terms of conditional variance $\sigma_{t}^{2}$ can be rewritten as follows:

$$
b(L) \sigma_{t}^{2}=a+\left[b(L)-\phi(L)(1-L)^{d}\right] \varepsilon_{t}^{2}
$$

The above model is referred to as a FIGARCH $(m, d, q)$ model, which was introduced by Baillie et al. [27]. Comparing the parameter $d$ as interval $(0,1)$ with that of fractional difference, it can be concluded that the former is to model the short-run dynamics of volatility, while the latter captures the long-run characteristics of volatility. The operator $(1-L)^{d}$ can be rewritten as follows:

$$
\begin{aligned}
& (1-L)^{d}=\sum_{k=o}^{\infty} \frac{\Gamma(k-d)}{\Gamma(k+1) \Gamma(-d)} L^{k} \Rightarrow \\
& =1-d L+\frac{(1-d)(-d)}{2} L^{2}+\frac{(2-d)(1-d)(-d)}{3 !} L^{3}+\ldots
\end{aligned}
$$

In that case, when $\mathrm{k}$ is large enough, we have

$$
\frac{\Gamma(k-d)}{\Gamma(k+1)} \approx k^{-d-1}
$$


Equation (22) indicates that the effect of shocks on conditional volatility is reduced by a hyperbolic rate. This means that shocks have long-term memory [5, 10, 25].

\subsubsection{Multivariate form}

To extend the univariate FIGARCH model to a multivariate framework - in other words, to introduce fractionality into a multivariate GARCH model - it is better to recall the variance equations of the $\operatorname{GARCH}(1,1)$ and $\operatorname{FIGARCH}(1, d, 1)$, and the characteristics of the multivariate diagonal $\operatorname{GARCH}(1,1)$. Using a simplified and more convenient notation, they can be expressed as:

$$
\begin{aligned}
& \sigma_{t}^{2}=\omega+\beta \sigma_{t-1}^{2}+\alpha \varepsilon_{t-1}^{2} \\
& \sigma_{t}^{2}=\omega+\beta \sigma_{t-1}^{2}+\left(1-\beta L-(1-\phi L)(1-L)^{d}\right) \varepsilon_{t}^{2} \\
& H_{t i j}=\omega_{i j}+\beta_{i j} H_{t i j-1}+\alpha_{i j} \varepsilon_{t-1, i} \varepsilon_{t-1, j}
\end{aligned}
$$

Considering $H_{t}$ and $\varepsilon_{t} \varepsilon_{t}^{t}$ as symmetric matrices indicates that $\omega_{\mathrm{ij}}, \alpha_{\mathrm{ij}}$ and $\beta_{\mathrm{ij}}$ should be symmetric as well. This leads to a total of $3 \frac{n(n+1)}{2}$ free parameters for the multivariate model. One way of developing a FIGARCH model into a multivariate framework would be to write the FIGARCH equations for each element of the conditional covariance equation as

$$
H_{t i j}=\omega_{i j}+\beta_{i j} H_{t-1 i j}+\left(1-\beta_{i j} L-\left(1-\phi_{i j} L\right)(1-L)^{d_{i j}}\right) \varepsilon_{t i} \varepsilon_{t j}
$$

The above equation is a direct generalisation form of the bivariate to multivariate framework introduced by Teyssière [28]. Unfortunately, the probability function of this specification is very sensitive to the number of parameters. There are $\frac{n(n+1)}{2}$ parameters in the model, and it appears that for $n=3$, the probability function has already become so flat that it causes serious difficulties in estimating the model.

Therefore, a more frugal specification of the long term memory component was proposed. Development of the FIGARCH model to the multivariate framework is analogous to development of the GARCH, but the fractionality operator $(1-L)^{d}$ is kept a scalar. Thus in Equation (26), only $\omega, \beta,(1-\beta L)$ and $(1-\phi L)$ are generalised to a matrix form; accordingly, a variance equation for the suggested model is $[5,10,28]$ :

$$
H_{t i j}=\omega_{i j}+\beta_{i j} H_{t-1 i j}+\left(1-\beta_{i j} L-\left(1-\phi_{i j} L\right)(1-L)^{d}\right) \varepsilon_{t i} \varepsilon_{t j}
$$

Obviously, this specification can be obtained from the previous one by applying $d_{i j}=d$ and considering a common structure in the long term memory components. There are several reasons for upgrading this specification. First, for similar empirical financial series, it is theoretically reasonable to assume a common long term memory structure. Second, it has been found that the degrees of long term memory are close to each other in the volatility of similar empirical financial series. For example, using semi-parametric estimation techniques, Teyssière [28] considered a common degree of long term memory for the volatility of daily exchange rates of the German Mark and the British pound against the U.S. dollar. Similar results were obtained in a bivariate FIGARCH framework. For further details, the reader may refer to [29].

\section{THE PROPOSED MODEL}

To develop a multivariate fractional $\operatorname{BEKK}$, consider the $\operatorname{BEKK}(1,1)$ model introduced in Equation (14). As mentioned previously, in order to extend the GARCH $(1,1)$ to FIGARCH 
$(1, \mathrm{~d}, 1)$, the term $\alpha_{i j} \varepsilon_{t-1, i} \varepsilon_{t-1, j}$ must be replaced by $\left[1-\beta_{i j} L-\left(1-\phi_{i j} L\right)(1-L)^{d_{i j}}\right] \varepsilon_{t i} \varepsilon_{t j}$, which can be rewritten as follows:

$$
\begin{aligned}
& {\left[1-\beta_{i j} L-\left(1-\phi_{i j} L\right)(1-L)^{d_{i j}}\right] \varepsilon_{t i} \varepsilon_{t j}=} \\
& =\varepsilon_{t i} \varepsilon_{t j}-\beta_{i j} L\left(\varepsilon_{t i} \varepsilon_{t j}\right)-(1-L)^{d}\left(\varepsilon_{t i} \varepsilon_{t j}\right)+\varphi_{i j} L(1-L)^{d}\left(\varepsilon_{t i} \varepsilon_{t j}\right)
\end{aligned}
$$

To adapt $\operatorname{BEKK}(1,1)$ to fractional $\operatorname{BEKK}(1, \mathrm{~d}, 1)$, the term $A^{* T} \varepsilon_{t-1}^{T} \varepsilon_{t-1} A^{*}$ must be replaced by:

$$
\varepsilon_{t}^{T} \varepsilon_{t}-G^{* T}\left(\varepsilon_{t-1}^{T} \varepsilon_{t-1}\right) G^{*}-(1-L)^{d} \varepsilon_{t}^{T} \varepsilon_{t}+A^{* T}(1-L)^{d} \varepsilon_{t-1}^{T} \varepsilon_{t-1} A^{*}
$$

As a result, the following model is obtained:

$$
\begin{aligned}
& H_{t}=C^{* T} C^{*}-G^{* T}\left(\varepsilon_{t-1}^{T} \varepsilon_{t-1}\right) G^{*}+\left[1-(1-L)^{d}\right] \varepsilon_{t}^{T} \varepsilon_{t}+ \\
& (1-L)^{d} A^{* T}\left(\varepsilon_{t-1}^{T} \varepsilon_{t-1}\right) A^{*}+G^{* T} H_{t-1} G^{*}
\end{aligned}
$$

This multivariate developed model is derived from the BEKK model, in which the long-term parameter (d) is taken into account. Furthermore, in order to consider the long-term memory parameter, the developed model estimates this parameter through the modelling process. The long term memory term $(1-L)^{d}$ should be converted into its Maclaurin expansion:

$$
(1-L)^{d}=1-d L+\frac{d(d-1)}{2 !} L^{2}-\frac{d(d-1)(d-2)}{3 !} L^{3}+\ldots
$$

The complexity of the problem arises from the fact that the estimation of the parameters is in contrast to trivariate models (with an increased number of equations) and bivariate models.

\section{ESTIMATION METHOD}

Since the most common approach for estimating the GARCH models is based on the maximum likelihood principle (see [24] or [30]), this approach is adopted for estimating the proposed multivariate FIGARCH model. The maximum likelihood estimator for the parameter $\theta$ of the model can be obtained by maximising the likelihood function for the given sample $\varepsilon_{t(\forall ; 1,2, \ldots, T)}$.

$$
\ln L(\theta)=\sum_{t=1}^{T}\left(-\frac{1}{2} \ln \left(\operatorname{det}\left(H_{t}\right)\right)-\frac{1}{2} \ln (\sqrt{2 \pi})^{n}-\frac{1}{2}\left[\varepsilon_{t}^{\prime} H_{t}^{-1} \varepsilon_{t}\right]\right.
$$

where $H_{t}$ is obtained by iterating the variance equation of the model. This relates $H_{t}$ to $\varepsilon_{t-j}$ and perhaps $H_{t-j}$. In other words, the structure of Equation (30) is used in the loglikelihood function of Equation (31).

To begin programming, all parameters to be estimated are defined. These parameters include all components of matrices $A^{*}, G^{*}, C^{*}$, and also the fractional difference parameter (d). As the size of the problem increases, the number of the parameters to be estimated increases as well. Therefore, estimating the parameters via econometric 
software becomes difficult. To tackle this problem, the PSO described in the following subsection is used.

\subsection{Particle Swarm Optimisation (PSO)}

PSO is a computational approach, initially proposed by Eberhart and Kennedy [31]. It is inspired by the social behaviour of birds flocking or fish schooling to find a rich source of food. In this approach, a swarm consisted of a number of particles flying around in an $\mathrm{N}$ dimensional search space. In the case of the considered log-likelihood maximisation, each particle plays the role of a solution, including the model parameters that need to be estimated. At first, a univariate $\operatorname{GARCH}(1,1)$ model is estimated for each time series. Then, the derived estimation results are used to define the initial values of the diagonal matrices,

$$
A^{*}, G^{*}, C^{*} \text {, and the time series residuals of } \varepsilon_{1 t}, \varepsilon_{2 t}, \varepsilon_{3 t} \text {. }
$$

To move from one solution to a new one, PSO uses a velocity vector that simultaneously determines the direction of the fly and the steps of the move. The position of each particle is updated through Equation (33). Following [30] and [32], the modified velocity update presented in Equation (34) was used, which had a better performance and convergence rate than the original PSO.

$$
\begin{aligned}
& X_{i j}(t+1)=X_{i j}(t)+v_{i j}(t+1) \\
& \mathrm{V}_{\mathrm{ij}}(\mathrm{t}+1)=\chi \times \mathrm{v}_{\mathrm{ij}}(\mathrm{t})+\chi \times \mathrm{C}_{1} \times \operatorname{rand}_{1} \times\left(\operatorname{pbest}_{\mathrm{ij}}(\mathrm{t})-\mathrm{X}_{\mathrm{ij}}(\mathrm{t})\right)+ \\
& \left.\chi \times \mathrm{C}_{2} \times \operatorname{rand}_{2} \times \operatorname{gbest}_{\mathrm{ij}}(\mathrm{t})-\mathrm{X}_{\mathrm{ij}}(\mathrm{t})\right)
\end{aligned}
$$

where:

$$
\begin{aligned}
& \chi=\frac{2}{\phi-2+\sqrt{\phi^{2}-4 \phi}}, \\
& \phi=C_{1}+C_{2}>4
\end{aligned}
$$

Figure 1 summarises the main steps of the PSO method.

\section{Procedure1 PSO ()}

\section{Begin}

1. Randomly generate a set of initial points of the size popsize;

3. for $\mathrm{t}=1$ to maxiteration do

1. Evaluate the particles;

2. Update personal best position of each particle (pbest);

3. Update global best position (gbest);

4. Velocity Update();

5. Position_Update();

6. Update $\overline{ }-\mathcal{}$;

7. end(for)

End.

Figure 1: Main steps of the PSO method

\section{THE EXPERIMENTAL RESULTS}

To investigate the performance of the proposed multivariate FIGARCH model estimated by PSO, three stock indices - those of the automobile industry, leasing, and machinery and equipment - were considered. In this research, the price index of the three groups in the Tehran Stock Exchange was used for experimental modelling. These indices included the automotive and parts manufacturing industry index, the financial intermediations (leasing) index, and the machinery and equipment index. Also, daily data for this case study were 
gathered in the period from 20 August 2006 to 14 May 2012. For each index, the market value is given in Table 1.

Table 1: Value market per selected parameter

\begin{tabular}{l|c}
\hline \multicolumn{1}{c|}{ Selected index } & Average value (Million Dollars) \\
\hline Automotive \& parts manufacturing industry & 1256 \\
Financial intermediations (leasing) & 125 \\
Machinery \& equipment & 218 \\
\hline
\end{tabular}

The following cases were taken into account while choosing the three mentioned indices:

A: There were at least three companies in each related group. There were also groups with only one or two companies in the Tehran Stock Exchange. The low number of companies in a group caused the index to be severely affected by the return and volatility changes of those companies.

B: They were size-sorted. This means that these indices were selected and sorted according to the size of their own subsidiaries. In other words, these indices included, respectively, large, medium, and small companies. According to the studies referred to, the volatility first enters the larger stock and then influences the smaller stock.

\subsection{Statistical features of the data (return of indices)}

Before return modelling, the statistical properties of return distribution should be examined. For this purpose, the statistical properties of the return distribution for the studied indices are presented in Table 2 . As observed in this Table, the daily average return of the automotive and parts manufacturing industry index and its standard deviation were 0.001408 and 0.00785 respectively from 20 August 2006 to 14 May 2012.

Table 2: Statistical features of the data (daily return of indices)

\begin{tabular}{lcccc}
\hline \multicolumn{1}{c}{ Index } & Average & Standard deviation & Skewness & Kurtosis \\
\hline Automotive \& parts manufacturing industry & 0.001408 & 0.00785 & 1.64587 & 36.42158 \\
Financial intermediations (leasing) & 0.002025 & 0.01705 & -0.084654 & 21.18723 \\
Machinery \& equipment & 0.000458 & 0.008427 & 1.75846 & 84.15871 \\
\hline
\end{tabular}

By comparing the standard deviation value and the average, one may realise that this variable did not have a high volatility during the study period. Distribution of this time series had a skewness of 1.645 , showing a skewness to the right. Furthermore, kurtosis of the return distribution was 36.42, which was much higher than the kurtosis of a normal density function: its diagram had a fat tail and high peak. Figures 2, 3, and 4 show return distribution diagrams that correspond to the automotive and parts manufacturing industry, financial intermediations (leasing), and machinery and equipment indices, respectively.

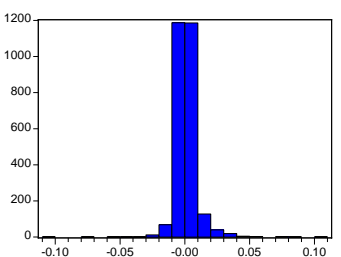

Figure 2: Distribution of return automotive \& parts manufacturing industry index

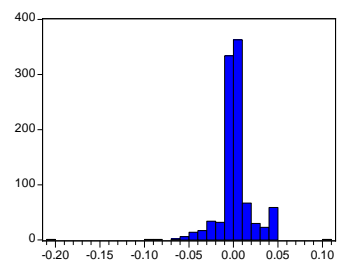

Figure 3: Distribution of return financial intermediations (leasing) index

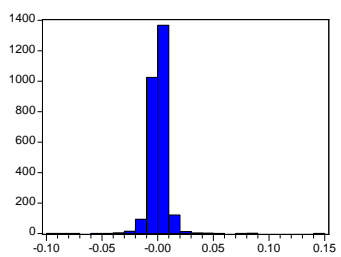

Figure 4: Distribution of return machinery \& equipment index 


\subsection{The long-term memory test}

Rescaled range (R/S) statistics and the test based on the GPH estimator by Geweke and Porter-Hudak, were used in order to test the long term memory property in three time series. Under GPH test and R/ S statistics, the null hypotheses indicate the absence of long term memory, and the opposite hypothesis shows the existence of long term memory in time series. So, if the test statistics do not have a significant difference from zero, the null hypothesis or absence of long term memory cannot be rejected. Derived results from each of the two mentioned tests are presented in Table 3.

Table 3: GPH test for determining the long-term memory parameter

\begin{tabular}{|c|c|c|c|c|c|}
\hline \multicolumn{4}{|c|}{$\begin{array}{l}\text { Test for Long term memory: GPH Test } \\
\text { Test for Long term memory: Modified R/ S Test }\end{array}$} & \multicolumn{2}{|c|}{$\begin{array}{l}\text { Significant } \\
\text { Level }\end{array}$} \\
\hline Index (return) & $\begin{array}{l}\mathrm{R} / \mathrm{S} \\
\text { Test }\end{array}$ & $\begin{array}{l}\text { GPH } \\
\text { Test }\end{array}$ & d & $95 \%$ & $99 \%$ \\
\hline $\begin{array}{l}\text { Automotive \& parts manufacturing } \\
\text { industry }\end{array}$ & $2.4518^{* *}$ & $3.5491^{* *}$ & 0.3481 & $*$ & ** \\
\hline Financial intermediations (leasing) & $2.1284^{*}$ & $3.4584^{* *}$ & 0.4218 & $*$ & ** \\
\hline Machinery $\&$ equipment & $2.7684^{* *}$ & $2.7139 *$ & 0.3179 & * & ** \\
\hline
\end{tabular}

According to the results in Table (3), existence of long term memory was confirmed at a 99 per cent confidence level for the return index of the automotive and parts manufacturing industry and financial intermediations (leasing). According to the test results, existence of long term memory was confirmed at a 95 per cent confidence level for the machinery and equipment index instead of a 99 per cent confidence level. Considering the positive value lower than 0.5 that was obtained for the long term memory parameter (d), it is obvious that all three of the studied time series were stationary. As can be seen in Table 3, according to R/S statistics, two time series of the automotive and parts manufacturing industry and the machinery and equipment, which has a confidence level of 99 per cent, and the financial intermediations (leasing), which has a confidence level of 95 per cent, possess long term memory.

\subsection{Implementing the multivariate nonlinear model}

The parameters of the proposed fractional BEKK (FBEKK) and BEKK models were obtained by implementing the PSO method. In this study, three time series - those of of the automobile industry, financial intermediations (leasing), and machinery and equipment, were considered. According to Table 4, the estimated parameter value of long term memory (d) is equal to 0.281 . When $|d|>\frac{1}{2}$, the time series is non-stationary; when we have $0<d<\frac{1}{2}$, the time series are stationary and possesses long term memory. In the case of $-\frac{1}{2}<d<0$, the time series are stationary with short memory that, in some texts, is called antipersistent. It should be mentioned that this term was also classified in long term memory scope [34]. The difference in the estimated values of $d$ for various models also indicates that the models' various explanations of different shocks affect the persistency rate in the process of mean logarithmic time series [35]. In the FBEKK model, $\alpha_{i i}$ shows ARCH effect and $\alpha_{i j}$ represents the volatility transmission of variable $\mathrm{i}$ in the previous period to variable $\mathrm{j}$ in the current period.

This volatility transmission is measured by square residuals in return estimation models. $\beta_{i i}$ shows the GARCH effect and the stationarity of volatility in each of the series. Also, $\beta_{i j}$ represents the variances' volatility transmission of the variable $\mathrm{i}$ in the previous period to variable $\mathrm{j}$ in the current period. It should be mentioned that both $\alpha_{i j}$ and $\beta_{i j}$ may represent volatility transmission between the indices. Table 4 includes the estimation results of the BEKK and FBEKK models. 
Table 4: Comparison of estimated parameters of BEKK and FBEKK models

\begin{tabular}{|c|c|c|c|c|c|}
\hline \multirow[b]{2}{*}{ Coef.. } & \multicolumn{2}{|c|}{$\begin{array}{c}\text { BEKK } \\
\text { (Without consideration of long term } \\
\text { memory effect) }\end{array}$} & \multicolumn{2}{|c|}{ FBEKK } & \multirow[t]{2}{*}{$\begin{array}{c}\text { Status of estimated } \\
\text { parameters }\end{array}$} \\
\hline & $\operatorname{Pr}(>|t|)$ & Value & $\operatorname{Pr}(>|t|)$ & Value & \\
\hline$d$ & - & - & 0.0000 & 0.281 & \\
\hline$\alpha_{11}$ & 0.0000 & 0.88790 & 0.1085 & 0.142794 & $\begin{array}{l}\text { Significant in BEKK } \\
\text { model }\end{array}$ \\
\hline$\alpha_{12}$ & 7.257e-001 & 0.019941 & 0.0000 & 0.047349 & $\begin{array}{l}\text { Significant in FBEKK } \\
\text { model }\end{array}$ \\
\hline$\alpha_{13}$ & $6.586 \mathrm{e}-001$ & -0.05843 & 0.7320 & 0.053692 & $\begin{array}{l}\text { Insignificant in both } \\
\text { models }\end{array}$ \\
\hline$\alpha_{21}$ & 0.0000 & 0.038746 & 0.0000 & 0.788325 & $\begin{array}{l}\text { Significant in both } \\
\text { models }\end{array}$ \\
\hline$\alpha_{22}$ & 0.0000 & 0.723048 & 0.0000 & 0.384752 & $\begin{array}{l}\text { Significant in both } \\
\text { models }\end{array}$ \\
\hline$\alpha_{23}$ & 0.0000 & 0.074937 & 0.0000 & 0.473762 & $\begin{array}{l}\text { Significant in both } \\
\text { models }\end{array}$ \\
\hline$\alpha_{31}$ & $6.453 e-001$ & 0.031846 & 0.0008 & $\begin{array}{c}- \\
0.083579\end{array}$ & $\begin{array}{l}\text { Significant in FBEKK } \\
\text { model }\end{array}$ \\
\hline$\alpha_{32}$ & 3. 564e-001 & 0.04659 & 0.0000 & 0.086361 & $\begin{array}{l}\text { Significant in FBEKK } \\
\text { model }\end{array}$ \\
\hline$\alpha_{33}$ & 0.0000 & 0.64539 & 0.0000 & 0.457286 & $\begin{array}{l}\text { Significant in both } \\
\text { models }\end{array}$ \\
\hline$\beta_{11}$ & 0.0000 & 0.519027 & 0.3475 & 0.781333 & $\begin{array}{l}\text { Significant in BEKK } \\
\text { model }\end{array}$ \\
\hline$\beta_{12}$ & 4.578e-001 & -0.04637 & 0.7859 & $\begin{array}{c}- \\
0.058389\end{array}$ & $\begin{array}{l}\text { Insignificant in both } \\
\text { models }\end{array}$ \\
\hline$\beta_{13}$ & 6. $374 \mathrm{e}-001$ & 0.03789 & 0.3572 & 0.184730 & $\begin{array}{l}\text { Insignificant in both } \\
\text { models }\end{array}$ \\
\hline$\beta_{21}$ & 4.657e-001 & 0.00184 & 0.1638 & 0.047383 & $\begin{array}{l}\text { Insignificant in both } \\
\text { models }\end{array}$ \\
\hline$\beta_{22}$ & 0.0000 & 0.845931 & 0.0000 & 0.602647 & $\begin{array}{l}\text { Significant in both } \\
\text { models }\end{array}$ \\
\hline$\beta_{23}$ & 3.573e-002 & -0.27483 & 0.0000 & 0.463829 & $\begin{array}{l}\text { Significant in both } \\
\text { models }\end{array}$ \\
\hline$\beta_{31}$ & 6. 366e-001 & 0.47382 & 0.06374 & 0.017493 & $\begin{array}{l}\text { Insignificant in both } \\
\text { models }\end{array}$ \\
\hline$\beta_{32}$ & 3. 528e-001 & -0.54638 & 0.0000 & $\begin{array}{c}- \\
0.053286 \\
\end{array}$ & $\begin{array}{l}\text { Significant in FBEKK } \\
\text { model }\end{array}$ \\
\hline$\beta_{33}$ & 0.0000 & 0.75937 & 0.0000 & 0.68457 & $\begin{array}{l}\text { Significant in both } \\
\text { models }\end{array}$ \\
\hline
\end{tabular}

The FBEKK model converged after 86 iterations, and the log-likelihood estimator maximised by the Berndt-Hall-Hall-Hausman method (BHHH) was equal to 10643. Also, the BEKK model converged after 51 iterations, and the log-likelihood estimator was equal to 9054. According to Table $4, \alpha_{i i}$ and $\beta_{i i}$, which were estimated by the BEKK model, indicate that the amount of shocks transmission and stationarity in conditional volatility for the three surveyed indices was also significant.

In the FBEKK model, the amount of shocks transmission and stationarity in conditional volatility was significant only for the financial intermediations (leasing) and machinery and equipment indices. Furthermore, the estimation results of the BEKK model revealed that the volatility transmission only existed from the financial intermediations (leasing) index to the automobile industry index $\left(\alpha_{21}=0.038746\right)$. However, in the FBEKK model, there were volatility transmissions from the financial intermediations (leasing) index to the automobile industry index $\left(\alpha_{21}=0.788325\right)$, and also from the automobile industry index to the financial intermediations (leasing) index $\left(\alpha_{12}=0.047349\right)$. 
Also, $\alpha_{32}$ and $\beta_{32}$, which indicated volatility transmission from the machinery and equipment index to the financial intermediations (leasing) index, were not significant in the BEKK model.

However, in the FBEKK model, these parameters were significant ( $\alpha_{32}=0.086361$, $\beta_{32}=-0.053286$ ). Coefficients $\alpha_{23}$ and $\beta_{23}$ were significant in the BEKK and FBEKK models, meaning that in both models there was transmission volatility from the financial intermediations (leasing) to the machinery and equipment indices. It should be mentioned that there was no volatility transmission from the automobile industry to the machinery and equipment indices.

The BEKK model showed that volatility was significant in each index, but in the modelling of the volatility transmission, only the coefficients $\alpha_{21}, \alpha_{23}$, and $\beta_{23}$ were significant. These results, which were derived from the BEKK model, were in the same direction as those derived from the FBEKK model. Furthermore, since the FBEKK model included the long term memory parameter (d) in its formulation and estimated it, this model showed that $\alpha_{12}, \alpha_{31}, \alpha_{32}$, and $\beta_{32}$ were significant.

Moreover, transmission (lead-lag effect) was completely observed in the daily return. Leadlag effect is observable in many of the world's financial markets. A part of this effect, the specificity which is observed in daily efficiencies, could be due to the market's microstructure (such as non-simultaneous transactions and information flow). This is because larger stocks, due to their high volume of trades, usually represent the impact of recent news earlier. Another explanation of such phenomena is the more rapid response of large stocks to recent news that that of small stocks. This idea was introduced by [36].

\section{CONCLUSION}

Although GARCH approaches are theoretically preferred for estimating the variance and covariance matrix, the FIGARCH model needs many parameters. The necessity to estimate these parameters in the FIGARCH model restricts the ability to manage this approach in large-scale problems. The FIGARCH model also compensates for estimating convergence issues, which raise the problem of obtaining reliable estimations of all parameters. One result of such incidents is that multivariate FIGARCH systems are unrestricted and the results are only true in cases which comparatively small number of time series are provided. On the other hand, by establishing limits on parameters, their number can be reduced; however, these limitations themselves may cause new problems.

The results of the GPH test and R/S statistical test confirmed the existence of long term memory in three studied time series. According to all three financial time series with the long term memory feature, modelling should be done with a nonlinear method.

Volatility transmission was observed from the automotive and parts manufacturing industry index to the financial intermediations (leasing) index, and vice versa. However, transmission from the automotive and parts manufacturing industry index to the leasing index was more considerable, confirming the lead-lag effect in these two time series. Studying financial information related to those affiliated automotive and parts manufacturing companies also confirmed the obtained results, since the sale of only two subsidiaries of the automotive industry index (Iran Khodro Industrial Group and Saipa Group) was about 23 billion US\$. On the other hand, more than 40 percent of the automotive products were sold by leasing, which further confirmed the transmission of volatility from the automotive and parts manufacturing industry index to the leasing index.

Volatility transmission was also observed from the machinery and equipment index to the leasing index, and vice versa. It should however be noted that transmission from the 
machinery and equipment index to the leasing index was more considerable, confirming the lead-lag effect in these two time series. A transmission effect from the automotive and parts manufacturing industry index to the machinery and equipment index were observed as well. Considering the extensive and high volume of transactions in the automotive and parts manufacturing industry, its volatility transmission to the machinery and equipment index seemed to be natural. On the other hand, a two-way (bilateral) transmission between leasing and machinery originated in leasing operations and caused an indirect increase in demand that led investments toward this sector. Volatility transmission from the machinery and equipment sector and its categories - i.e., piece-makers and parts-manufacturers of raw materials - to leasing was also confirmed, based on the information flow theory in market and asynchronous transactions.

\section{REFERENCES}

[1] Tsay, R.S. 2005. Analysis of financial time series. $2^{\text {nd }}$ edition. USA: Wiley \& Sons, Inc. .

[2] Kroner, K.F. and Claessens, S. 1991. Optimal dynamic hedging portfolios and the currency composition of external debt. J ournal of International Money and Finance, 10(1), pp. 131-148.

[3] Hafner, C.M. and Herwartz, H. 2006. Volatility impulse responses for multivariate GARCH models: An exchange rate illustration. Journal of International Money and Finance, 25(5), pp. 719-740.

[4] Rombouts, J.V. and Verbeek, M. 2004. Evaluating portfolio value-at-risk using semi-parametric GARCH models. Cahier de Recherche, IEA(4), p. 14.

[5] Bauwens, L., Laurent, S. and Rombouts, J.V.K. 2006. Multivariate GARCH models: A survey. J ournal of Applied Econometrics, 21(1), pp. 79-109.

[6] Yang, W. and Allen, D.E. 2005. Multivariate GARCH hedge ratios and hedging effectiveness in Australian futures markets. Accounting \& Finance, 45(2), pp. 301-321.

[7] Karolyi, G.A. 1995. A multivariate GARCH model of international transmissions of stock returns and volatility: The case of the United States and Canada. Journal of Business \& Economic Statistics 13(1), pp. 11-25.

[8] Schüler, M. and Schröder, M. 2003. Systemic risk in European banking: Evidence from bivariate GARCH models. ZEW Discussion Papers.

[9] De Goeij, P. and Marquering, W. 2004. Modeling the conditional covariance between stock and bond returns: A multivariate GARCH approach. J ournal of Financial Econometrics, 2(4), pp. 531564.

[10] Hafner, C.M. and Herwartz, H. 2001. Volatility impulse response functions for multivariate GARCH models, Université Catholique de Louvain.

[11] Elder, J. 2003. An impulse-response function for a vector autoregression with multivariate GARCH-in-mean. Economics Letters, 79(1):, pp. 21-26.

[12] Altay-Salih, A.H., Pinar, M.C. and Leyffer, S. 2003. Constrained nonlinear programming for volatility estimation with GARCH models. SIAM Review 45(3), pp. 485-503.

[13] Kroner, K.F. and Sultan, J. 1990. Exchange rate volatility and time varying hedge ratios. Bentley College: Institute for Research and Faculty Development.

[14] Valiani, S. 2004. Application of multivariate GARCH in optimal dynamic hedging and international asset allocation. Basel, Switzerland: European Financial Management Association,.

[15] Brooks, C., Clare, A.D. and Persand, G. 2002. A note on estimating market-based minimum capital risk requirements: A multivariate GARCH approach. The Manchester School, 70(5), pp. 666-681.

[16] Tse, Y.K. and Tsui, A.K. 1999. A note on diagnosing multivariate conditional heteroscedasticity models. J ournal of Time Series Analysis, 20(6), pp. 679-691.

[17] Bollerslev, T. 1990. Modelling the coherence in short-run nominal exchange rates: A multivariate generalized ARCH model. The Review of Economics and Statistics, pp. 498-505.

[18] Minović, J. 2007. Application of multivariate GARCH models in Serbian financial market analysis. International Scientific Conference, Economic Faculty, Belgrade, Serbia.

[19] Kearney, C. and Patton, A.J. 2000. Multivariate GARCH modeling of exchange rate volatility transmission in the European monetary system. Financial Review, 35(1), p. 29-48.

[20] Ewing, B.T. and Malik, F. 2005. Re-examining the asymmetric predictability of conditional variances: The role of sudden changes in variance. J ournal of Banking \& Finance, 29(10), pp. 2655-2673.

[21] Malik, F. and Hammoudeh, S. 2007. Shock and volatility transmission in the oil, US and Gulf equity markets. International Review of Economics \& Finance, 16(3), pp. 357-368.

[22] Maringer, D. 2005. Portfolio management with heuristic optimization. Springer.

[23] Winker, P. and Maringer, D. 2009. The Convergence of Estimators based on Heuristics: Theory and Application to a GARCH model Computational Statistics, 24: 533-550

[24] Engle, R. 2002 New frontiers for ARCH models. Journal of Applied Econometrics, 17(5), 425-446. 
[25] Egle, R.F. and Kroner, K.F. 1995. Multivariate simultaneous generalized ARCH. Econometric Theory, 11(01), pp. 122-150.

[26] Nelson, D.B. 1990. Stationarity and persistence in the $\operatorname{GARCH}(1,1)$ model. Econometric Theory, 6(03), pp. 318-334.

[27] Baillie, R.T., Bollerslev, T. and Mikkelsen, H.O. 1996. Fractionally integrated generalized autoregressive conditional heteroskedasticity. J ournal of Econometrics, 74(1), pp. 3-30.

[28] Teyssière, G. 1999. Modelling exchange rates volatility with multivariate long-memory $A R C H$ processes. Discussion Papers, Interdisciplinary Research Project 373: Quantification and Simulation of Economic Processes.

[29] Pafka, S. and Matyas, L. 2001. Multivariate diagonal FIGARCH: Specification, estimation and application to modelling exchange rates volatility. CEU Dept. of Economics Working Paper (5).

[30] Hamilton, J.D. 1994. Time series analysis. Cambridge University Press.

[31] Eberhart, R. and Kennedy, J. 1995. A new optimizer using particle swarm theory. Proceedings of the Sixth International Symposium on Micro Machine and Human Science, IEEE.

[32] Eberhart, R.C. and Shi, Y. 2000. Comparing inertia weights and constriction factors in particle swarm optimization. Proceedings of the 2000 Congress on Evolutionary Computation, IEEE.

[33] Clerk, M. and Kennedy, J. 2002. The particle swarm-explosion, stability, and convergence in a multidimensional complex space. IEEE Transactions on Evolutionary Computation, 6(1), pp. 5873.

[34] Zivot, E. 2003. Modeling financial time series with S-Plus ${ }^{\circledR}$. Springer.

[35] Keshavarzhadad, G.R. and Samadi, B. 2010. Estimation and forecast return volatility in market exchange of Tehran and assessment methods estimate the value at risk: Using family $\mathrm{GARCH}$ model. J ournal of Economic Research, 86, pp. 43-64.

[36] Conrad, J. and Kaul, G. 1989. Mean reversion in short-horizon expected returns. Review of Financial Studies, 2(2), pp. 225-240. 